\section{Desafíos a la epidemiología (pasos para una epidemiología "Miltoniana")}

\section{Challenges to epidemiology (steps to a "Miltonian" epidemiology)}

\author{
A la memoria de Milton Santos
}

Dedicated to the memory of Milton Santos

\section{Resumen}

Se sostiene que uno de los grandes desafíos que enfrenta la Epidemiología contemporánea está situado en el campo teórico, y consiste esencialmente en la exigencia de revisar la conceptualización del objeto de la epidemiología dominante que reduce la salud de las poblaciones al comportamiento de los riesgos concebidos con abstracción de los vínculos particulares que los sujetos guardan con sus corporeidades geográficas y medioambientales. El artículo pretende reintroducir la perspectiva dialéctica que deja de lado la visión sustancialista de la realidad de las poblaciones de un lado y del medio ambiente, del otro lado, para proponer una visión estructural, funcional e histórica de ambos conceptos, desarrollando, en este sentido el espíritu de la obra del Gran Geógrafo Brasileiro.

Palabras claves: Ambiente. Epidemiología crítica. Epidemiología y globalización.

\footnotetext{
Juan Samaja

Universidad Nacional de Buenos Aires

Calle Gral. Güemes 729

(CP. 1641) Acassuso, Buenos Aires, Argentina

jsamaja@sinectis.com.ar
} 
This paper argues that one of the major challenges that contemporary Epidemiology has to face is at the level of theory. In essence, it is necessary to revise the abstract conceptualization of the dominant Epidemiology object, which has reduced the health of the population to behavioral risks, without taking into account the link that people have to their geographical and environmental corporities. This article then seeks to reinsert the dialectical perspective that leaves aside the substantialist view of population reality, on one side, and that of the environment, on the other, in order to propose a structural, functional and historical perspective of both concepts, developing, in this way, the spirit of the Great Brazilian Geographer's work.

Key Words: Environment. Critical epidemiology. Epidemiology and globalization.

\section{Introducción}

Voy a intentar un modesto aporte al debate sobre el tema: "Los desafíos que las transformaciones globales contemporáneas le plantean a la Epidemiología”. Le daré, en esta ocasión, al término "Epidemiología” una acepción más amplia que la usual, como sinónimo de "Ciencia de la Salud del Ser Social".

Antes de presentar las ideas particulares que quisiera defender haré una somera alusión a los presupuestos más generales implicados en el tema: es decir, a los "cambios globales en la sociedad y en el ambiente" empleando los escritos de intelectuales de reconocida autoridad. En particular, haré uso amplio de los escritos de uno de los más grandes intelectuales de todos los tiempos: me refiero a ese inmenso geógrafo brasileiro llamado Milton Santos, al mismo tiempo que hago propicia esta oportunidad para rendir honor a su obra y a su espíritu.

No puede resultar extraño que yo haya encontrado en los libros de Milton el modelo más adecuado para pensar mi intervención en este tema, dado que casi todos los libros de Milton estuvieron destinados a una tarea como ésta, a saber: examinar y responder a los desafíos que las transformaciones sociales de la humanidad contemporánea le fueron planteando al conocimiento en general y a la Geografía, en particular.

He tomado, pues, de las ideas centrales de sus libro como un modelo para organizar mi pensamiento y formular los desafíos que yo creo que debemos afrontar en tanto epidemiólogos.

Una constante en el trabajo intelectual de Milton consistió en la permanente reflexión que va del examen de la actualidad social al papel que debe desempeñar el conocimiento para hacer de esa actualidad un presente menos doloroso y más promisorio para los hombres concretos. Por ello, es relativamente fácil encontrar en muchos capítulos de su obra el examen de estos dos asuntos o temas que coinciden exactamente con el tema que tenemos planteado:

- por un lado, el examen de esa masa de 
acontecimientos que llamamos genéricamente "globalización"; y

- por otro lado, sus interrogantes y sus respuestas a las funciones y las tareas que tiene planteadas el conocimiento científico.

Pareciera que el único punto en que las tareas de Milton se diferencia de la nuestra tiene que ver con las respectivas disciplinas: Milton se refiere de manera especial a la Geografía; nosotros en cambio, deberemos referirnos a la Epidemiología. Sin embargo, el examen que haremos (pese a su brevedad) nos llevará a concluir que esa "diferencia" es en gran parte aparente, ya que tanto la Geografía como la Epidemiología, cuando son examinadas con espíritu miltoniano (es decir, con espíritu dialéctico) muestran que tienen un único objeto y un único proyecto: el hombre concebido en su incesante proceso de totalización, y cuyo fin supremo es la realización de su ser social y de su ser libre, en tanto soberano de su destino. El hombre corporificado: como cuerpo orgánico y como cuerpo inorgánico (es decir, enlazado a la tierra, a las cuencas hídricas, a las máquinas, a los medios de comunicación...).

Una de las razones de esa convergencia en el objeto del conocimiento es de orden metodológico, y consiste en el imperativo de interdisciplinariedad o de transdisciplinariedad que rige de manera especial para las ciencias sociales. Al respecto escribió:

Nunca é demais insistir no risco representado por uma ciência social monodisciplinar, desinteressada das relações globais entre os diferentes vetores de que a sociedade é constituída como um todo ${ }^{1}$. (p. 19).

Pero, la otra razón de la convergencia entre Geografía y Epidemiología es de orden sustantivo: como trataré de mostrar en el final de mi exposición, el objeto de la Geografía miltoniana y de la Epidemiología que quisiéramos promover coinciden plenamente. En ambos casos está en juego el esfuerzo por pensar de manera histórica, concreta y dinámica la existencia humana total: es decir, como subjetividad corporificada/espacializada en todos los niveles de sus acciones y de sus objetividades. Para Milton el espacio no es sólo sistemas de objetos, sino en tanto resultantes y determinantes de sistemas de acciones. Si en cierta forma se puede decir que el gran imperativo cognitivo de Milton fue reintroducir los sujeto en el "espacio y en los objetos de la Geografía”, para nosotros, que levantamos el pensamiento de Milton como bandera de lucha científica, la gran tarea será reintroducir los objetos y los espacios en el "sujeto de las Ciencias de la Salud humana”. ¿Por qué? Porque el gran riesgo de la Epidemiología consiste en concebirse como una ciencia monodisciplinar que dice preocuparse por el bienestar subjetivo de los hombres, pero se desinteresa del papel que los espacios y los objetos concretos cumplen en ese bienestar.

En ambos casos, el imperativo es el mismo: bregar por la unidad esencial e histórica del ser humano con sus pre-requisitos materiales de trabajo, es decir, con los prerequisitos objetivos de la existencia humana, en tanto humana.

Regresemos al punto de partida. ¿Cómo caracteriza Milton al proceso de globalización? Y, ¿̇en qué medida este proceso ha exacerbado la alienación de los seres humanos, llevando a la inmensa mayoría de la humanidad a la pérdida total de su dimensión objetiva, de su corporeidad (orgánica e inorgánica)?

\section{Las transformaciones globales de la humanidad contemporánea}

El panorama general que presentan en la actualidad las sociedades contemporáneas, pese a su enorme variedad o diversidad locales, está atravesada por un mismo patrón ecuménico: la unificación de las economías nacionales de todos los países, a los dictados de los mercados de capital y a los centros del poder financiero mundial.

Ciertamente, como muy bien lo señala Milton Santo, esta actual mundialización de las historias "económicas" de las naciones 
del orbe no es un hecho enteramente nuevo. El nacimiento de este proceso de mundialización fue agudamente descripto por Marx. Vale la pena recordar algunos de las muestras de su prosa:

"Espoleada por la necesidad de dar cada vez mayor salida a sus productos, la burguesía recorre el mundo entero. Necesita anidar en todas partes, establecerse en todas partes, crear vínculos en todas partes. "Mediante la explotación del mercado mundial, la burguesía dio un carácter cosmopolita a la producción y al consumo de todos los países. Con gran sentimiento de los reaccionarios, ha quitado a la industria su base nacional. Las antiguas industrias nacionales han sido destruidas y están destruyéndose continuamente. Son suplantadas por nuevas industrias, cuya introducción se convierte en cuestión vital para todas las naciones civilizadas, por industrias que ya no emplean materias primas indígenas, sino materias primas venidas de las más lejanas regiones del mundo, y cuyos productos no sólo se consumen en el propio país, sino en todas las partes del globo. En lugar de las antiguas necesidades, satisfechas con productos nacionales, surgen necesidades nuevas, que reclaman para su satisfacción productos de los países más apartados y de los climas más diversos, en lugar del antiguo aislamiento de las regiones y naciones que se bastaban a sí mismas, se establece un intercambio universal, una interdependencia universal de las naciones. Y esto se refiere tanto a la producción material, como a la producción intelectual, La producción intelectual de una nación se convierte en patrimonio común de todas.” ${ }^{2}$ (T.I, p. 25) (La cursiva ha sido agregada. JS.)

Es importante destacar la gran sensibilidad con la que Marx y Engels previeron el papel particularísimo y descollante que jugaría la ciencia en el desarrollo de la tecnología, y por ende, en los procesos de valoración y de la reproducción del capital.

Es decir, que el proyecto de mundia- lización de las relaciones económicas, sociales y políticas -como lo resalta Miltonno es de ahora: comienza con la extensión de las fronteras del comercio al principio del siglo XVI, avanza por saltos a través de los siglos de expansión capitalista para finalmente ganar cuerpo en momento en que una nueva revolución científica y técnica se impone y en que las formas de vida en el Planeta sufren una repentina transformación: las relaciones del Hombre con la Naturaleza pasan por una fase turbulenta, gracias a los formidables medios colocados a disposición del hombre. Por eso, según Milton Santos, recién ahora es posible hablar de mundialización de la economía. Anteriormente sólo cabe hablar de internacionalización ${ }^{1}$. (p. 12)

Los rasgos con los que Milton caracteriza al proceso que llamamos "globalización" son los rasgos resultantes de una especie de "fundamentalismo de la economía liberal" que se expresa como universalización de la producción, incluyendo la producción agrícola, la producción industrial y el marketing; se expresa como universalización de los intercambios; universalización del capital y de sus mercados, universalización de las mercaderías, de los precios y del dinero como mercadería patrón; universalización de las finanzas y de las deudas; universalización de los modelos de utilización de los recursos por medio de una universalización relacional de las técnicas; universalización del trabajo, esto es, del mercado del trabajo, y el trabajo improductivo; universalización del ambiente de las empresas y de las economías; universalización de los gustos y del consumo de vestidos y alimentos; universalización de la cultura y de los modelos de vida social, universalización de una racionalidad al servicio del capital erigida en moralidad igualmente universalizada; universalidad de una ideología mercantil concebida desde el exterior; universalización del espacio; universalización de la sociedad mundializada y del hombre, pero, como dice Milton, del hombre amenazado por una alienación total, lo que simplemente quiere decir, de "un hombre que ha perdido toda 
soberanía sobre las condiciones objetivas de su existencia ${ }^{1}$. (p. 14)

En síntesis, la maduración completa de aquel proceso cuyo nacimiento describieron Marx y Engels se ha plasmado en un mundo en que, según Milton Santos, la ley del valor mundializada dirige la producción total por medio de las técnicas dominantes, las que utilizan los desarrollos científicos o intelectuales, tal como lo previeron los fundadores del Materialismo Histórico.

Vivemos num mundo em que a lei do valor mundializado comanda a produção total, por meio das produções e das técnicas dominantes, aquelas que utilizam esse trabalho científico universal previsto por Marx². (p. 14)

Según esto, un rasgo descollante de las transformaciones globales contemporáneas y que son peculiares del siglo XX es la llamada "revolución científico técnica". Los rasgos particulares con que las llamadas ciencias positivas ingresaron a la cultura dominada anteriormente por el estilo metafísico o especulativo de conocimiento, fueron mostrando cada vez más su carácter operatorio y su particular afinidad con las necesidades de las innovaciones en los procedimientos industriales. El paso de los años sólo puso de relieve de manera completa esta particular dependencia del "estilo científico de conocimiento" con la sociedad capitalista que le dio origen. Pero el siglo XX mostró de manera extrema hasta qué punto podía la ciencia pasar a formar parte de un único sistema de desarrollo con la innovación tecnológica.

Trata-se agora de um verdadeira interdependência entre a ciencia e a técnica, contrariamente ao que acontecia outrora. De fato, como observou R. Richta, hoje á ciencia precede a técnica', embora sua realização lhe seja cada vez mais subordinada. A tecnología daí resultante é utilizada em escala mundial, e nada mais conta a não ser uma busca desenfrenada do lucro, onde quer que as condições o permitam. Este é um dado fundamental da situação atual. (Op.cit., p. 17)
De esa manera se ha instaurado una tendencia notable: una porción enorme de las investigaciones, en todo el mundo está orientada a crear nuevas técnicas, según criterios de rentabilidad, y no a resolver genuinos problemas de conocimiento. Los científicos son evaluados según el número de patentes y no según las leyes o explicaciones descubiertas. Pareciera que la llamada investigación científica contemporánea:

... Apunta, además, no a resolver problemas específicamente científicos, sino a utilizar los conocimientos, los métodos, el savoir faire científicos para crear nuevos procedimientos industriales, poner a disposición de la economía nuevos medios, fabricar nuevos ingenios militares o contribuir a realizaciones encaminadas al desarrollo de una región o de un país. En una palabra, la investigación se ha convertido en un factor de poder, tanto en el ámbito económico como en el directamente político ${ }^{3}$. (p. 23)

Pero, como lo resalta Milton, citando a Heilbroner, "las máquinas no hacen historia" ni tampoco se puede hablar de "un determinismo tecnológico". De allí que sea importante hacer ver con toda la fuerza deconstructiva del método dialéctico, que el término "revolución científico-técnica" es una manera alienada de hacer referencia a la trama de relaciones sociales que la humanidad ha venido "tejiendo" en los últimos siglos y en las últimas décadas y que, pese a todas las apariencias, sigue siendo $s u$ propia historia. Una historia que tiene un sentido social, aunque quede oculto detrás de la forma fetichizada con que se nos muestra en el mundo de las realizaciones técnico-científicas.

Esa apariencia de historia de cosas que presenta la globalización bajo el nombre de "revolución científico-técnica", es parte misma iy muy importante! del desafío que tenemos planteado como representantes del conocimiento y la Epidemiología. Las transformaciones globales se presentan como sifueran un destinofijado por la Ciencia (reificada como una especie de "un saber sin 
sujeto") y las Técnicas (también fetichizadas como un "hacer sin sujeto"). La pseudocateogoría de "revolución científico-técnica" sin duda contribuye a justificar, cuando no logra ocultar, la contracara o reverso de esa mundialización o universalización: a saber, la creciente particularización de la riqueza, de los espacios; la particularización del poder político, del poder financiero, militar, etc., que acompaña permanentemente a la globalización.

La construcción de un mundo de cosas universalizado contrasta con la creciente construcción de un mundo de relaciones sociales dramáticamente particularizados en dos partes que se alejan cada vez más una de otra: hombres pobres y ricos; naciones pobres y ricas; territorios pobres y ricos...

\section{Los desafíos al conocimiento en general y a la Epidemiología en particular}

Más allá de que queramos o no involucrarnos o implicarnos en la Globalización (es decir, en las transformaciones globales de la sociedad y el medio), ESTAMOS INVOLUCRADOS; ESTAMOS IMPLICADOS. La globalización se ha construido también con el protagonismo de los intelectulales, de los científicos y no sólo de los empresarios. Por acción o por omisión, estamos siendo responsables de lo que viene ocurriendo. La ciencia esta siendo cooptada por una tecnología dirigida por la ley dek valor (por la finalidad de la renta del capital) y no del bienestar humano. En esas condiciones, la ciencia se pone al servicio de los intereses de las empresas transnacionales y no de los pueblos. Sirve al capital (es decir, al hombre enajenado) y no a los pueblos (individuos, comunidades, naciones, es decir, a los hombres histórico-concretos). Se fragmenta, por imposición del criterio instrumental que lo dirige, de modo que "las técnicas substituyen al método"; la eficacia substituye a la verdad.

Acá tenemos planteado el enorme desafío que Milton Santos vino proclamando desde hace décadas:
Un saber comprometido con interesses e instintucionalizado em função de conhecimentos estritamente delimitados acaba por sofrer uma fragmentação cujo resultado é, não autonomia desejábel das disciplinas científicas, mas a sua separação. A evolução econômica agrava essa distância e nos afasta cada vez mais de um enfoque global e da visão crítica que ele permite. Então, o trabalho do cientista se vê despojado de seu conteúdo teleológico e debe ser feito segundo uma óptica puramente pragmática para atender aos que pedem as pesquisas ou dirigem as instituções de ensino. (Op.cit., p. 18)

El conocimiento es una función esencial a la autoregulación de la vida en todas sus formas. La percepción; las creencias religiosas; los sistemas metafísicos o filosóficos y las llamadas ciencias positivas son formas diversas de conocimiento que hunden sus raíces en las variadas formas de vida que ha ido construyendo la historia humana. Ciertamente no son formas aisladas sino que han ido enfrentándose, motivándose y sintetizándose las unas con las otras. Es indudable que estas formas de conocimiento, en tanto históricas, presentan una presencia que en el tiempo es sucesiva: primero aparecieron todas las formas de la inteligencia sensorio motora; luego la inteligencia representacional, lingüistizada con la vasta gama de saberes de las culturas ágrafas; es decir, las sociedades preestatales. Y posteriormente, con la emergencia de las luchas de clase y de las complejas mediaciones estatales, advino el vasto mundo de las civilizaciones: la escritura, las Matemáticas, la Filosofía y el nacimiento del concepto; de la Idea Lógica.

Necesito hacer esta referencia al nacimiento de la Idea Lógica, tal como la alumbró la cultura grecolatina, porque allí se forjaron los horizontes más generales de la noción de Ciencia como saber de la verdad. Es cierto que esa ciencia no es exactamente la Ciencia Positiva tal como quedará orientada por el siglo de Isaac Newton, pero no hay duda que su horizonte como saber racional, con vocación teórica, es decir, con la pretensión 
de ir más allá de las meras apariencias, y lograr la iluminación de cada uno de los hechos desde una Visión del Todo se forjó en la Grecia Antigua. Milton, precisamente, sostiene que es esta dimensión teórica de la ciencia la que está siendo severamente menoscabada por la servidumbre de la investigación científica a los planes de inversiones rentables. El esfuerzo por la teoría, por la visión totalizadora de la realidad, es precisamente, el blanco favorito de los ataques al conocimiento. Es frecuente observar cómo se desalientan los esfuerzos teóricos en nombre del valor de la práctica utilitaria. Pero, como escribió Jean Ladrière:

La teoría no es una vana mirada sobre un mundo que estuviera completamente a la vista, que no fuera sino un centelleo que se ofrece a la contemplación, ni un ejercicio insignificante que dejase a las cosas tal como están, y que no hiciera más que agregar a la desdicha de la vida la copia inútil de un reflejo estéril; la teoría es el esfuerzo sublime del «logos» en el hombre para elevar una vida contingente, aparentemente abandonada a la fatalidad y entregada al aniquilamiento, hasta la sublime condición de una vida soberana... ${ }^{3}$. (p. 27)

Max Weber también advirtió con claridad de qué manera la cultura del capitalismo empujaba a la Ciencia hacia el abandono de los grandes ideales de la Ciencia, tal como lo habían delineado los filosófos griegos ${ }^{4}$.

\section{Hacia una revisión de las categorías fundamentales de la Epidemiología}

Por todo lo dicho, quisiera detenerme en esta ocasión de manera exclusiva en las exigencias teóricas centrales que la Epidemiología sigue arrastrando desde su misma fundación y que hoy más que nunca está conminada a resolver. Nuevamente acá creo estar siguiendo el ejemplo de Milton, quien dedica un extenso primer capítulo, en una de sus últimas obras, a "uma ontología do espaço, es decir a reexaminar sus "noçoes fundadoras".

De manera semejante a cómo él ataca el desafío a la Geografía poniendo su mira en las categorías centrales de su disciplina (aquellas que contribuyen de manera principal a determinar el objeto de la Geografía, esto es el "espacio"), análogamente creo que mi aporte podría consistir en sumarme a aquellos que buscan promover una renovada reflexión sobre las nociones primordiales que configuran el objeto de la Epidemiología*, empezando por la categoría de "población" o de "colectivo" como sujeto primordial.

Pero, ¿̇por qué revisar categorías tan útiles y obvias como las de "población" o “colectivo”? ¿Por qué hacer filosofía (más particularmente, ontología) sobre estas palabras cuando lo que se necesita es solamente hacerlas funcionar para describir los hechos que están padeciendo los miembros de esas poblaciones o esos colectivos?

Acá es donde el modelo de Milton nos alienta a desafiar este rechazo de la teoría. De manera semejante a como Milton cuestiona la categoría ontológica de "espacio" concebido como sistemas de objetos con abstracción de las acciones humanas que le dan ser, así la Epidemiología crítica debiera cuestionar la categoría de "población" concebida como agrupamientos individuales con abstracción de los sistemas de objetos implicados en sus acciones.

\section{Las respuestas de una "epidemiología miltoniana" a los desafios de la ciencia en tiempos de la globalización}

Para una epidemiología forjada en el espíritu de Milton Santos, estas "cuestiones" ontológicas dejan de ser mero "pasatiempo"

\footnotetext{
* Entre los autores que han producido importantes obras reflexivas sobre estos temas, es preciso nombrar en un lugar destacado a Neomar Almeida Filho, Celilia Minayo, a Ricardo Ayres, Luis Castiel ..., pero también muchos otros que sería largo enunciar.
} 
intelectual para transformarse en un instrumento necesaria para enfrentar la amenaza de alienación total del hombre contemporáneo. Para una "epidemiología miltoniana" estas cuestiones se transforman, para decirlo con palabras de Ladrière, en "una sublime condición de la vida soberana”.

A esta amenaza de alienación total, el espíritu miltoniano nos incita a contestar con una audaz revisión de las pseudo-categorías del cientificismo, del positivismo, y mediante la elaboración y el aprestamiento operatorio de nuevas categorías que reflejen con mayor sensibilidad e integralidad el mundo de la praxis humana, en tanto humana.

\section{El puesto de las "categorías" en el conocimiento}

Pero, ¿qué son las categorías? Desde Kant sabemos que son formas de llevar a la unidad del pensamiento la diversidad y pluralidad de las experiencias. Ahora bien, esas formas no surgen de la nada o por generación espontánea: son posibilitadas e introducidas en el mundo del lenguaje y del pensamiento por la praxis misma. Ellas traducen al lenguaje las maneras recurrentes con las que los hombres unifican, sintetizan los productos de sus acciones. De modo, que las categorías, en un sentido más profundo, son formas de actuar del hombre en tanto ser integral, es decir, no sólo viviente individual, sino también, comunal, político $y$ societal) (Sobre la diferencia entre estos últimos conceptos me referiré más adelante). Esto implica que si la praxis de una clase está empujada por sus propios intereses a separar a ciertos sujetos de ciertos objetos, a tornar invisibles ciertos nexos que obstaculizan la consecución de sus fines particulares, etc., entonces, su actividad teórica tenderá a construir pseudo categorías, es decir, meras palabras que parecieran estar destinadas a llevar las experiencias a la unidad de su pensamiento verdadero, cuando lo cierto es que está permanentemente ocultando esa unidad, y realzando y consagrando la separación, la división, la abstracción.

La Epidemiología, en tanto matriz disci- plinaria de la comunidad de los epidemiólogos, es por sobre todo el conjunto de categorías con las que ellos buscan encontrar la unidad de los hechos diversos que están en juego en la determinación de los procesos que afectan la salud-enfermedadatención de los individuos, de los colectivos, de las poblaciones.

Como lo dije anteriormente, uno de los rasgos dominantes del estilo que fue imprimiendo las ciencias positivas (postnewtonianas) a los investigadores, fue un creciente desinterés por el examen de sus categorías, reemplazando el esfuerzo crítico que habían inaugurado los filósofos anteriores, por una especie de metafísica del sentido común del empresario capitalista. El nominalismo, el convencionalismo, el relativismo, el empirismo, etc., desalojaron al trabajo del conceptoque habían inaugurado los grandes espíritus de la Ciencia Antigua: Sócrates, Platón, Aristóteles y prolongaron sus homólogos en la ciencia moderna y contemporánea: Vico, Leibniz, Kant, Hegel, Marx, Habermas, Piaget, Teilhar de Chardin, von Bertalanfy, D. Bohm, Morin, Capra, etc.

La Epidemiología, como ciencia positiva, nace en esa cultura científica newtoniana y sus categorías obvias son los "individuos" y sus "residencias", concebidas como lugares separados y homogéneos al interior de un espacio absoluto, vinculados entre sí por relaciones causales de naturaleza externa, es decir, mecánicas.

Sin duda, estos desarrollos del conocimiento fueron recibidos como notables progresos, por dos razones íntimamente vinculadas entre sí:

- por su gran facilidad para ser llevadas a una práctica de carácter ingenieril; $\mathrm{y}$

- por ser sumamente afines al "sentido común" de una sociedad crecientemente dominada por la economía de mercado. El modelo dominante en el mundo feudal fue el de la mística religiosa y la metafísica platónica; un modelo que, a falta de un término universalmente aceptado, podemos llamar "comunalista", consistente en interpretar las cosas como dimensiones inseparables de una totalidad ideal, pero sólo 
presupuesta místicamente y no examinada críticamenteni comprobada empíricamente.

Un modelo en donde todo depende de todo no deja lugar para la acción del ingeniero y en consecuencia peca de puramente especulativo. El nuevo modelo que promovió la naciente sociedad burguesa se puso en las antípodas del platonismo comunizante y totalizante: fue y sigue siendo un modelo atomista y contractualista. Para este modelo todo existe como entidad separada, independiente de las restantes entidades, y que de manera convencional entablan relaciones externas, constituyendo agregados provisorios. Su analogía fundante es la máquina mecánica.

La dialéctica, a cuyo linaje pertenece el pensamiento de Milton Santos, constituye un intento de recuperar las ideas parcialmente correctas que contienen los dos modelos opuestos anteriores (comunalismo y contractualismo), pero mediante una revisión radical del método para pensar sus respectivos contenidos. Admite la unidad suprema del universo, pero, al mismo tiempo reconoce la constante proliferación y emergencia de partes en conflictos; la separación, la división en fragmentos o elementos, la crisis y el paso a nuevas formas de reunificación; a la formación de nuevas unidades, con reconfiguración de sus propios componentes. Para esta concepción, la noción fundamental, es la noción de TOTALIDAD.

A noção de totalidade é uma das mais fecundas que a filosofia clássica nos legou, constituindo em elemento fundamental para o conhecimento e análise da realidade. Segundo essa idéia, todas as coisas presente no Universo formam uma unidade. Cada coisa nada mais é que parte da unidade, do todo, mas a totalidade não é uma simples soma de partes. As partes que formam a Totalidade não bastam para explicá-la. Ao contrário, é a Totalidade que explica as partes $^{1}$. (p. 93)

La categoría de "totalidad" es en sí misma la expresión de una síntesis:la síntesis entre la unidad y la pluralidad. Pero, como tal síntesis no es una mera yuxtaposición de sentidos sino el nuevo sentido que incluye como momento principal la escisión en muchas subunidades o partes, el conflicto entre tales partes y el paso a nuevos niveles de integración, en totalidades más compleja, más desarrollada. Éstas totalidades constituyen así nuevas realidades, irreductibles a las anteriores. Tales nuevas realidades, a su turno, también entrarán en crisis o en fases de escisión y deberán poder encontrar nuevas formas de totalización..., o estarán condenadas a desaparecer. De allí la necesidad de evitar que la noción de Totalidad se confunda sin más con la mera unidad o con el mero conjunto. Milton propone al respecto seguir a Sartre, quien introdujo el término "totalización” para expresar la categoría más rica que incluye la nota esencial de proceso productivo, reproductivo y transformativo:

...Não vemos nessa totalidades - escribió L. Goldmann- alguna coisa de já existente e de dado, mas somente um fim a ser atingido pela acão, única coisa capaz de criar a comunidade humana, o nós, e o conjunto do universo, o cosmos 5 . (p. 94)

\section{Pasos para una revisión de la categoría de población: de la población abstracta a los niveles de integración del ser social}

Luego de este largo rodeo recién me encuentro en condiciones de hacer algunas propuestas más precisas acerca de cómo avanzar en los desafíos que la Epidemiología debería afrontar en el terreno teórico.

Sabemos que los problemas de la salud son los de las crisis que afectan a la reproducción de la vida humana en todas sus formas. Pero, ¿ icuáles son esas formas primordiales en las que existe la vida humana? ¿Cómo se desarrollan las totalidades humanas; cómo se interfieren; cómo se transforman; como se totalizan incesante y dramáticamente?

Sobre estas cuestiones, pese a que hay mucho escrito, la inmensa mayoría de los trabajadores de la salud no tenemos todavía 
suficientes escenarios de debate o de enseñanzas, ni tampoco suficientes libros que nos ayuden a pensarlos. Se nos ha entrenado para ubicar conjuntos poblacionales en los espacios; para identificar y ponderar factores operantes en esos espacios; para contar los casos como subconjuntos de esas poblaciones y obtener tasas, como medidas de riesgos de la salud, etc. Pero no tenemos ni motivación ni habilidades suficientes para revisar los supuestos ontológicos que están operando en las nociones de "conjunto poblacional", de "factor", de "caso", de "riesgo", etc. Las implicancias semánticas e ideológicas de estas nociones fundadoras de la epidemiología ("población", "medio ambiente", "factor", "tasa”, "riesgo", etc.) siguen estando en el cómodo y confortable mundo del sentido común burgués (es decir, en el modelo del mercado). Las ciencias de la salud (y con ellas la Epidemiología) se construyeron en la cultura moderna en torno a la idea de sujeto individualy en torno a la idea complementaria que la población es sólo eso: una asociación de sujetos individuales que constituyen meros mero conjuntos. $Y$ debemos reconocer que ésa es una idea tan elemental, tan de "sentido común" que tendemos a admitirla sin ninguna reflexión como la base natural del pensamiento práctico y teórico. Sin embargo, lo cierto es que antes que llegara a ser posible el individuo real (es decir, ese sujeto que tiene potestad sobre su cuerpo, su pensamiento, y sus posesiones como para entrar en relaciones contractuales) debieron suceder muchísimas cosas, a lo largo de una prolongada y compleja construcción histórica: como evolución natural y como prehistoria e historia social.

La noción abstracta de "población”, tal como es empleada en la literatura estadística, (esa sombrainseparable de la Epidemiología) no tiene ninguna capacidad para hacer comprensible la profunda diferencia que hay entre una población de moléculas y un organismo unicelular; entre una población de células y un organismo metazoario; entre una poblacion de metazoarios y un organismo biocomunal (es decir, una organización familiar de animales); entre una población de familias y una organización comunal humana o tribal; entre una población de tribus o linajes y una organización estatal nacional, y entre una población de naciones y la organizción de la sociedad civil globalizada.

La diferencia que va de una mera población a un organismo o a una totalidad organizada, es la misma diferencia que los antiguos veían entre el cuerpo y el alma: el cuerpo sin alma era para el pensamiento tradicionalista (neoplatónico), un puro agregado de huesos y músculos. Análogamente, una "población" cuyo principio organizativo no sea indicado explícitamente, es sólo eso: un rejuntado de entidades sin "alma", sin esencia, sin entidad propia. Una Epidemiología que no se pronuncie expresamente sobre la índole total de su objeto corre el riesgo de estar perdiendo el alma misma o el sujeto mismo de su tarea científica.

Cada uno de estos niveles de integración organísmica (organismo viviente, biocomunidad, comunidad cultural, estado nación; sociedad civil globalizada) comporta un salto de totalidad y un proceso constante de totalización mediante el cual se puede mantener como tal sujeto históricoconcreto .

El sentido común está bien dispuestos a aceptar que hay una infinita diferencia entre una colonia de millones de vivientes unicelulares y un individuo multicelular. La diferencia no estriba en la naturaleza de los constituyentes de una colonia de bacterias y una lombriz: tanto los protozoarios de la colonia como las células que integran el cuerpo de la lombriz son vivientes unicelulares. La diferencia estriba en que en un caso sólo son un "agregado" de individuos que mantienen intacta su autonomía, y apenas dan lugar a un conjunto que carece en sí mismo de toda capacidad para dirigirse con cierta autonomía, y, en cambio en el otro caso, son partes de un todo, y este todo existe y estabiliza patrones propios de acción mediante el doble mecanismos de conservara sus componentes, pero a condición de suprimir su autonomía, en aras de nuevos patrones normativos que crean una nueva totalidad. 
Es así como se inauguran en el universo nuevas regiones de entidades. De tal modo, cuando se formaron los metazoarios, la composición "ontológica” de la Tierra dio un salto para adelante: se enriqueció con nuevos tipos de seres o entidades. Ylo mismo podemos decir de la aparición de las biocomunidades (por ejemplo, las colmenas, las jaurías, las bandadas...). Es indudable que tales biocomunidades son nuevas entidades, son nuevos sujetos compuestos por metazoarios que han conservado mucho de su ser anterior, pero a condición de haber tenido que suprimir su autonomía, para someterse a las normas del nuevo ser (del organismo) emergente. Precisamente este nuevo tipo de ente es lo que denominamos "organismo biocomunal" o "familia".

Ahora bien, ¿son las biocomunidades (enjambres, jaurías, bandadas...) genuinos sujetos?" Es decir, ¿̇son substancias en sí mismas o son meras accidentes o propiedades de las únicas sustancias genuinas, a saber los individuos que las integran?" Esta cuestión es central para poder repensar de manera dialéctica la relación entre Sociedad y medio ambiente.

Mi respuesta es que los metazoarios, las comunidades, los estados nacionales y la mismísma sociedad civil "son sujetos igualmente genuinos"; "son substancias igualmente genuinas". No aceptar este tratamiento igualitario importa crear un problema insoluble, a saber: ¿cuál es el individuo que tiene el exclusivo privilegio de ser considerado "genuino sujeto", "genuina sustancia": ¿los metazoarios?; ¿los protozoarios?; ¿las moléculas?; los átomos; las partículas subatómicas, y cuáles o en qué nivel nos detendremos finalmente?

Frente a esta aporía que crea la pregunta por LA SUSTANCIA GENUINA, surge la antítesis relativista que levanta como bandera el antisubstancialismo, es decir, el puro relativismo: no hay sustancias, sólo hay relaciones o interacciones entre (pseudo) términos relativos. En la realidad no hay autonomías: sólo hay mutuas dependencias.

No sería difícil mostrar cómo el antisubstancialismo también se pierde en innumerables oscuridades y contradicciones, ya que desde su mismo punto de partida nos enfrenta a la paradoja de admitir relaciones sin términos.

No es posible en este espacio desarrollar un análisis de los límites de estas categorías, pero alcanza con recordar la solución que Kant aportó al mostrar que ambas categorías (sustancia/relación) sólo realizan su contenido cuando se reúnen en la categoría de "comunidad" o "causalidad recíproca":

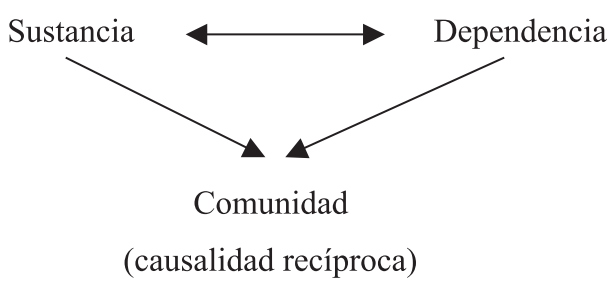

La propuesta kantiana fue luminosa porque vino a sostener que las entidades reales no deben ser concebidas como cosas ni tampoco como puras relaciones entre cosas, sino como comunidades organizadas. Es decir, como las relaciones entre las relaciones, es decir, las funciones que construyen totalidades.

Kant, con esta manera de sintetizar las categorías antitéticas de "sustancia" y "causalidad", puso las bases para concebir los hechos reales no como cosas ni como meras redes interminables de relaciones, sino como totalidades complejas integradas por partes recíprocamente interdependientes y por ende, como funciones de una organización. Dicho más simplemente: como totalidades organizadas o "sistemas cerrados en cuanto a ciclos y abiertos en cuanto al medio".

Según esta poderosa idea, todo lo que puede ser considerado una "entidad substancial”, es decir, como una entidad que subsiste a través de sucesivas alteraciones o cambios, debe ser concebido como una totalidad de partes, de relaciones entre partes, y de procesos en las que esas relaciones se reproducen como totalidad organizada.

Estas totalidades procesuales, a su turno, pueden pasar a formar parte de totalidades mayores, lo que supone que sus deter- 
minaciones propias son susceptibles de dirección o sobredeterminación, y lo que implica la supresión de su autonomía con conservación de su propio fundamento entitativo. Un gran discípulo de Kant, Hegel, denominó este complejo proceso por el cual una sustancia pasa a formar parte de otra sustancia “Aufhebung", término alemán que en castellano se traduce, precisamente, como: supresión, conservación, superación.

Entre las entidades sustanciales del universo no hay, entonces, ni completa inherencia ni completa dependencia. Hay comunicación, porque el universo está compuesto de acciones comunicacionales, es decir, de sustancias, de relaciones entre las sustancias, y de relaciones entre las relaciones, es decir, de funciones o valores significantes. Las totalidades organizadas contienen el germen y el desarrollo de la categoría de subjetividad, como la instancia de conocimiento, en tanto función necesaria a la autoregulación. En este sentido, todas las sustancias son también sujetos de conocimiento aunque de distintos niveles de integración: el individuo (en tanto metazoario) es un tipo de sujeto sensorial y perceptual; la biocomunidad o comunidad animal es un sujeto mimético; la comunidad humana o cultural es sujeto de la eticidad y de tradiciones narrativas; el Estado es sujeto del conocimiento reflexivo o espistémico; la Sociedad Civil es sujeto de la ciencia y del saber tecnológico... Todo esto, sin embargo, no obsta para aceptar que cuando estamos hablando de individuos no podamos decir que cada Comunidad (por ejemplo, cada familia) es un atributo de cada uno de ellos (es decir, un medio externo o un entorno); cuando dirigimos nuestra atención a las Comunidades (= familias), no podamos decir que los individuos, por un lado, y las totalidades sociales, por otro lado) son atributos de ellas (componentes y entornos, respectivamente), etc., etc.
El paso que hemos dado con estas proposiciones nos ofrece un panorama de la realidad radicalmente diferente al cientificista newtoniano: para éste la realidad se presenta como un mundo plano constituidos por entes primitivos, un espacio abstracto de interacción y los sujetos, como conciencias agazapadas fuera del mundo. Todos ellos con cierta potestad para ingresar a diversas asociaciones puramente externas: facilitadas o interferidas por la presencia de factores favorables o antagónicos. Para la versión dialéctica de la ontología, en cambio, la realidad se presenta como un mundo de procesos, cuya historia formativa los ha organizado en numerosos estratos conectados entre sí, con su incesantes esfuerzos reproductivos o de totalización, a veces exitosos y otras veces fallidos: siempre dramáticos. Como un mundo de procesos en donde se va realizando la función cognoscitiva de acuerdo con las diversas grados de desarrollo de la vida misma, de modo que la subjetividad deja de ser concebida como una instancia externa al mundo, para transformarse en un rasgo esencial, inherente a toda complejidad organizada ${ }^{6}$. (p. 364)

\section{Pasos para una revisión dialéctica de la categoría de Medio Ambiente}

En la ontología newtoniana (positivista) el medio ambiente se identifica con el espacio vacío que es "medio" (es decir, "mediador") sólo porque es ocasión de que los elementos entren en relaciones entre sí, pero, en todo caso se mantiene externo a los entes mismos que intermedia. En la ontología dialéctica, que es estratigráfica y dinámica al mismo tiempo, la categoría de "medio ambiente" adquiere diferentes modalidades, según sean los niveles de integración en los que fijemos nuestra atención y según sea la dirección del análisis. Observemos el siguiente diagrama: 


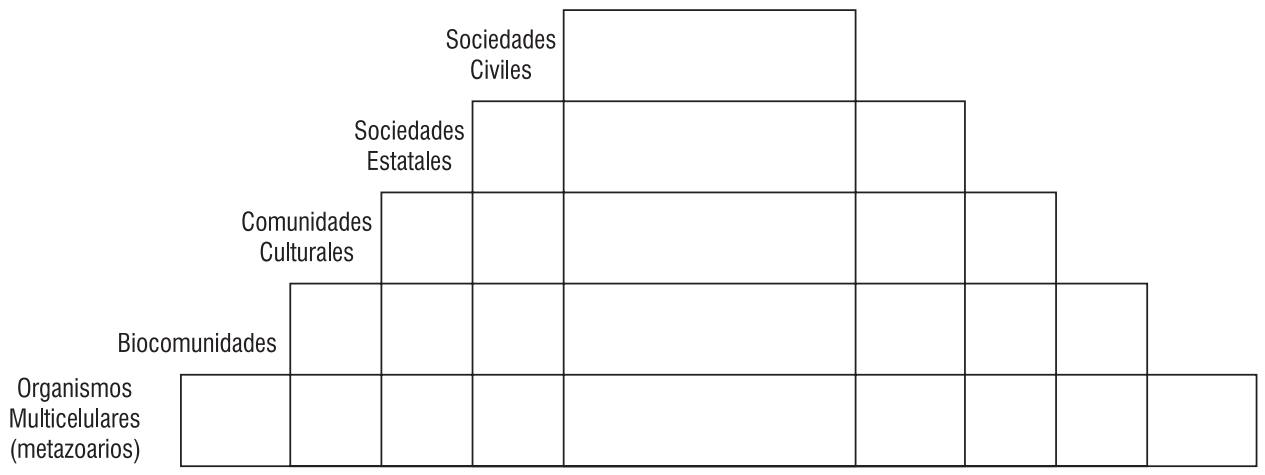

(Para una mejor comprensión de las categorías incluidas en este diagrama, cfr. Samaja 20007) (In order to better understand the categories included in this diagram, refer to Samaja 20007)

Cada estrato presenta un nivel de procesos organísmicos entre los cuales se han dado y se siguen dando procesos de supresión, conservación y superación. Como se puede apreciar en una lectura ascendente, cada estrato anterior oficia de "substratum" del posterior, el cual se erige a partir de él, aunque reorganizándolo según las leyes emergentes de su propio nivel. Cada uno de ellos (excepto el último) aparece, al menos en una cierta parte de su totalidad, "atrapado" por el nivel superior: es decir, suprimidos, conservados y superados por un nuevo nivel de totalización.

De la simple descripción se desprende, metafóricamente hablando, que en una dirección "ascendente", el vínculo que hay entre los estratos es de constitución. En cambio, en una dirección descendente, el vínculo debe describirse como regulación.

Decimos que las biocomunidades están constituidas o integradas por metazoarios; las comunidades humanas están constituidas por biocomunidades (o núcleos familiares); los estados o naciones están constituidas por diversas comunidades culturales, etc. En la dirección "descendente”, en cambio, decimos que los estados nacionales regulan la vida de sus comunida- des; que las comunidades regulan la vida de sus grupos familiares; las familias regulan la vida de sus miembros; los organismos multicelulares regulan la vida de sus tejidos y células, etc. Ciertamente, esta regulación no es absoluta y no alcanza a la totalidad de los estratos "inferiores" sino sólo a aquellos que se transformaron en sus elementos constitutivos.

Pues bien, si ahora intentamos definir el lugar de lo que llamamos "medio ambiente" comprobaremos que la respuesta ya no puede ser lineal. Fijemos nuestra atención en los dos siguientes niveles: i) el nivel de los individuos (como organismos multicelulares) y ii) las células.

El mundo de los viviente unicelulares se divide en dos grupos: 1 . el grupo de los que están fuera de los organismos multicelulares (los protozoarios, en sentido estricto, que prosiguen siendo relativamente autónomos) y el de los que están suprimidos, conservados y superados como constituyentes del organismo de un metazoario.

Ahora bien, si tomamos como punto de referencia al organismo multicelular (es decir, al individuo metazoario), podemos decir que las células que habitan fuera del organismo (por ejemplo, el vasto mundo de

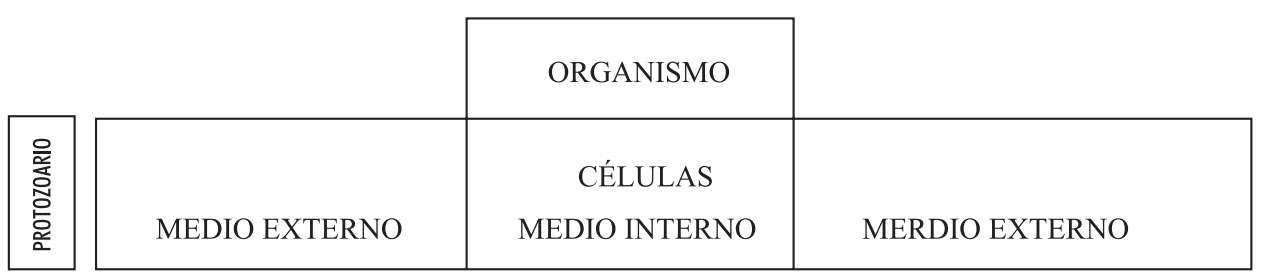


las poblaciones bacterianas con sus respectivos habitats) integran lo que habitualmente llamamos el medio externo del organismo, a diferencia de las células constitutivas (es decir, las que habitan dentro del organismo), que son consideradas medio interno. Es fácil admitir que tanto el medio externo como el medio interno ponen condiciones a la existencia del organismo total. Ambos son lados complementarios de lo que podemos llamar "su medio condicionante", en la medida en que las células (externas, como las bacterias; internas, como los leucocitos) ponen condiciones a los procesos del organismo total, pero no lo determinan, en el sentido en que no producen ni motivan las acciones o fines específicos del organismo.

Si ahora tomamos como punto de referencia al organismo, pero no en relación con el nivel celular, sino con su nivel superior, es decir, con las biocomunidades (por ejemplo, la colmena, o la misma familia humana), debemos reconocer que también constituye un medio ambiente para el organismo, y que en cierta forma puede designarse como "externo". Pero salta a la vista que no es un medio condicionante, sino medio determinante. No sólo pone condiciones, sino que regula y es fuente de determinaciones esenciales para el organismo. En este sentido vale la afirmación de Milton Santos cuando escribe: "é a Totalidade que explica as partes".

El organismo individual depende del medio ambiente familiar para realizarse como miembro familiar. El medio familiar es determinante de los comportamientos de los miembros de una familia, de manera semejante a como el medio organísmico individual es medio determinante de su población leucocitaria.

Ahora bien, en un sentido semejante al que empleamos al hablar del medio condicionante, podemos decir que también en el medio determinante pueden discriminarse elementos internos y elementos externos, en el sentido en que una parte crucial de las acciones y componentes del medio familiar se interiorizan (introyectan) y pasan a constituir parte del aparato psíquico del miembro familiar, pero una parte importante permanece exterior a él. Para decirlo mediante un ejemplo, los padres existen tanto como padres internalizados (representados o semióticos), pero también subsisten como padres externos (reales y, por ende, con capacidad de realizar acciones causales sobre los hijos).

\section{Algunas precisiones sobre estas tesis (a desarrollar)}

Las dos tesis principales de esta última parte se sintetizan de la siguiente manera:

- La díada totalidad-sujeto / medio ambiente es relativa al objeto que se escoge como plano focal: si el objeto focalizado son las comunidades de cierta nación, el concepto abstracto de "medio ambiente" se concreta o especifica así:

Medio ambiente determinante: Contexto socio-político (Estado Nación)

Totalidad-sujeto (plano focal): Comunidad Medio ambiente condicionante: Contexto físico-químico-biótico

Si, por el contrario, se toma como plano focal a una Nación particular, entonces, las comunidades pasan a integrar el contexto condicionante, ocupando el lugar del contexto determinante la sociedad supranacional:

Medio ambiente determinante: Contexto internacional (Sociedad Civil globalizada)

Totalidad-sujeto (plano focal): Nación Medio ambiente condicionante: Contexto físico-químico-biótico-comunal

- La totalidad sujeto se relaciona con sus medio-ambientes (condicionantes y determinantes) de dos maneras, ya que la historia en la que se ha formado, implicó procesos de mediación que lo "entretejen" actualmente con sus interfaces jerárquicas inferiores y superiores de dos maneras: a. de manera interna, ya que ella misma está constituída 
por y regula a las formaciones anteriores, y constituye a y es regulada por las formas superiores; $y b$. de manera externa, ya que la totalidad sujeto encierra sólo una pequeña porción del estrato inferior (ver los desbordes laterales del diagrama), y es superado por los estratos superiores (ver el desborde vertical del diagrama).

Finalmente, ¿qué conclusiones se pueden derivar de esta revisión dialéctica de las categorías de Sociedad y Ambiente? Creo que al menos se pueden desprender tres conclusiones generales:

\section{Primera conclusión:}

La conclusión más importante y la que comporta consecuencias más trascendentes para las investigaciones sociales en general y epidemiológicas en particular, es que lo que se llama "medio ambiente" no es de ninguna un mero "entorno" de la totalidad-sujeto, sino un componente de su historia y una inherencia de su complejidad organizada.

Dicho de otra manera: lo que llamamos "el medio" no es el mero negativo de... o lo externo a... una totalidad-sujeto dada (sea un organismo individual, una comunidad o un estado); tampoco es otro sermeramente yuxtapuesto. El medio ambiente es uno de los términos de la relación de los varios momentos que va construyendo la historia formativa de la realidad. Estos términos son resultado de las transformaciones epigenéticas (de una génesis estratificante y reconfigurante).

Totalidad-sujeto y medio ambiente sólo pueden ser entendidos como lados de una morfogénesis en paralelo de todas y cada una de las interfaces jerárquicas.

\section{Segunda conclusión:}

Analizado de modo dialéctico, el medio adquiere un contenido y una forma, según los cuales se comporta como condicionante o determinantey opera mediante una particular dialéctica entre una parte externa (medio externo) y una parte interna (medio interno)

\section{Tercera conclusión:}

Finalmente, el método dialéctico permite una más rica interpretación de los problemas ambientales al permitir una jerarquización y una valoración particular de las diversas contradicciones, identificando aquella contradicción en donde se acumula el sentido de tragedia de la vida de cada pueblo y de cada época.

En la medida en que la realidad existe en concreto como procesos de totalización en diferentes niveles de integración, entre ellos están sucediendo constantemente procesos de tensión, de conflictos, de rupturas y de resoluciones transformadoras: destructivas o constructivas de nuevas formaciones históricas.

Cuando se busca comprender los procesos reales de manera concreta, la noción de "medio ambiente" se transforma necesariamente en la noción de "situación", en la medida en que este concepto evoca de manera más expresiva, el vínculo histórico y semiótico que entraman a la totalidad-sujeto con sus mediaciones históricas.

Todo el contenido dramático de la identidad narrativa del universo y del hombre se remite a estas tensiones en las interfaces jerárquicas en las que se configura el misterio y la pasión de la subjetividad como función cognosctiva. La subjetividad, como inherencia de toda totalidad-organizada es siempre eso: una encrucijada y todos los grandes períodos de la historia han padecido de alguna de ellas de manera paradigmática.

Ahora bien, en todo conjunto de contradicciones siempre es posible (y necesario) identificar alguna contradicción como "la contradicción principal”, que cifra, por así decirlo, la tarea primordial del momento histórico, o el sentido de la situación planteada. Por ejemplo, podríamos decir que la encrucijada de la Grecia clásica estuvo dada por las tensiones entre el orden de los linajes tribales y la polis naciente (tal como lo expresa, por ejemplo, la tragedia de Sófocles, Antígona). La encrucijada del Renacimiento europeo consistió en los enfrentamientos entre los clanes de la Sociedad Feudal y el 
nacimiento del estado burgués con su apoteosis del individuo de la naciente sociedad contractualista, tal como lo encontramos dramatizado, por ejemplo, en Romeo y Julieta de Shakespeare. La tragedia de la sociedad burguesa en plena revolución industrial pareciera haberse expresado de manera paradigmática en la tensión dramática entre las familias del orden comunitario, de un lado, y las demandas de la fuerza de trabajo, como ingrediente esencial de la sociedad civil o del desarrollo capitalista de otro lado, tal como lo plasmaron autores como Víctor Hugo o Máximo Gorki, etc.

En esta misma tesitura es posible sostener que la encrucijada contemporánea la estamos atravesando en medio de las tensiones convulsivas entre la Sociedad Civil (=sociedad capitalista) globalizadaylos Estados Nacionales subdesarrollados o (neo) coloniales. La tragedia contemporánea consistiría, según esto, en la caída o desarticulación de las nacionalidades dominadas. Para nuestras naciones latinoamericanas, por caso, su situación estaría dada por este "medio ambiente determinante" constituido por la globalización (el capital internacional planetarizado) y la expropiación de todas las condiciones de existencia de los estados nacionales, de sus comunidades y de susindividuos.

En definitiva, creo que los desafíos más apremiantes que afrontan las ciencias sociales, y en particular la Epidemiología tienen que ver la necesidad de repensar al medio ambiente y a las poblaciones desde una perspectiva “miltoniana”, esto es, como situación histórica y como proyecto de liberación.

\section{Referencias}

1. Santos M. Metamorfoses do espaço habitado. São Paulo: Ed. Hucitec; 1997.

2. Marx K, Engels F. La Ideología Alemana. Montevideo: Editorial Pueblos Unidos; 1955.

3. Ladrière J. El Reto de la Racionalidad. Salamanca: Editorial Sígueme/Unesco; 1977.

4. Weber M. El Político y el Científico. Madrid: Editorial Alianza; 1980.

5. Santos M. A Natureza Do Espaço. São Paulo: Ed. Hucitec; 1996.
6. Teilhar de Chardin P. El fenómeno humano. Madrid: Editorial Taurus; 1967.

7. Samaja, J. Aportes de la Metodología a la reflexión epistemológica. En Esther Díaz (editora): La Posciencia. El conocimiento científico en las postrimerías de la modernidad. Editorial Biblos. Buenos Aires. 2000. p. 151-80.

Recebido em: 24/07/2002 Aprovação em: 23/11/2002 